\title{
Becoming familiar with hereditary transthyretin amyloidosis, a treatable neuropathy
}

\author{
Conhecendo melhor a amiloidose transtirretina hereditária, uma neuropatia tratável \\ Laura Obici?
}

'Amyloidosis Research and Treatment Centre, Fondazione IRCCS Policlinico San Matteo, Pavia Italy.

Correspondence:

Laura Obici; Amyloidosis Research and Treatment Centre, Fondazione IRCCS Policlinico San Matteo, Viale Golgi, 19, 27100 Pavia, Italy; E-mail: l.obici@smatteo.pv.it

Conflict of Interest: The author received speaker and consulting fees from Alnylam, Akcea and Pfizer.

Received 20 August 2018; Accepted 27 August 2018

(cc) BY

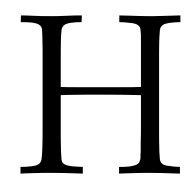
ereditary transthyretin (TTR) amyloidosis is a rare, adult-onset, autosomal dominant disease caused by misfolding and extracellular amyloid deposition of variant forms of the circulating transport protein transthyretin. Originally described according to the predominant clinical presentation as familial amyloid polyneuropathy (FAP) or familial amyloid cardiomyopathy, it is now called by the name of the amyloidogenic protein ${ }^{1}$. Not merely a nosological exercise, the current classification highlights the systemic nature of a phenotypically heterogeneous but single disease ${ }^{2}$ and reflects the likely unique underlying molecular pathway ${ }^{3}$.

Since tafamidis, the first pharmacological therapy for the treatment of hereditary transthyretin amyloid polyneuropathy was approved in Europe in 2011, disease awareness has significantly improved worldwide, with patients increasingly being identified in regions where the disorder was not previously recognized. The THAOS registry, the largest longitudinal observational study for TTR amyloidosis, was launched in 2007 and has now enrolled over 4,000 patients in 59 centres from 18 countries ${ }^{4}$. However, hereditary TTR amyloidosis still remains widely under-diagnosed, not only in countries where its prevalence is very low but also in the so-called "endemic" areas, including Portugal and Brazil, where it has been traditionally observed in large pedigrees sharing a common genetic ancestry.

In this issue of the Journal, Pinto et al. ${ }^{5}$ report the first Brazilian recommendations for the diagnosis and treatment of TTR-FAP, aiming at both raising awareness among health professionals and increasing cohesion in the clinical management of the disease across the country. Neurologists from different Brazilian centres gathered to share their expertise and establish a consensus for optimal diagnosis, effective multidisciplinary approach and appropriate therapeutic interventions. Not long ago, similar guidelines were proposed in Europe and Japan respectively, establishing expert networks for further regional collaborative studies ${ }^{6.7}$.

The educational relevance of this position paper, endorsed by the Brazilian Academy of Neurology, should be acknowledged, particularly in face of the growing availability of novel, targeted therapeutic options. These now urge a prompter diagnosis to allow the timely treatment of neurological, cardiac and other systemic manifestations. In fact, it has been clearly established that therapy is much more effective in the early stages of the disease ${ }^{8,9}$. Whereas a significant family history usually drives the suspicion in young adults developing the typical small-fibre and autonomic neuropathy associated with the most frequent and highly penetrant Val30Met mutation, a long diagnostic delay occurs in apparently sporadic cases with a later presentation that often mimics other common acquired disorders ${ }^{10}$. These patients mostly carry a non-V30M TTR gene variant and represent the rule in all countries that are not endemic for TTR-FAP ${ }^{11}$. Intriguingly, genotypes other than $\mathrm{V} 30 \mathrm{M}$ have barely been reported to date in Portugal and Brazil. Considering the large Brazilian population, its multi-ethnic background and the well-established genetic heterogeneity of the TTR gene, it is likely that patients with non-Val30Met mutations associated with a late-onset, mixed neurological and cardiologic phenotype are present in Brazil as well. In this respect, the low sensitivity of tissue biopsies in detecting amyloid deposits in late-onset, compared to early-onset, patients may further explain the limited identification of additional genetic variants ${ }^{6}$. As the authors recommend, genetic testing for TTR mutations should be performed even in the absence of a positive tissue biopsy and should always be considered in the differential diagnosis of an idiopathic or poorly responsive length-dependent sensorimotor neuropathy. Moreover, non-V30M variants are 
commonly associated with a mixed neurological and cardiac phenotype, making echocardiographic abnormalities easy and valuable red flags that should prompt further investigations to unveil a possible amyloid disease. Further advancements in the noninvasive diagnosis of hereditary TTR amyloidosis are offered by the still-unexplained but highly specific and selective cardiac uptake of bone scintigraphy tracers (i.e. DPD, PYP and HMDP) in patients with cardiomyopathy, that replace a positive tissue biopsy in the absence of other amyloidogenic proteins like a monoclonal gammopathy ${ }^{12}$.

Exciting therapeutic developments have recently paralleled this refinement in diagnostic capabilities. Last summer witnessed the publication of three successful, randomized, placebo-controlled trials ${ }^{13-15}$, whose results now finally open the way to consolidated treatment options for patients with stage II polyneuropathy and for patients with isolated cardiomyopathy.

The upcoming availability of these novel therapies and the possibility of combining them together or sequentially with the existing ones, will soon continue the need for additional, evidence-based recommendations that, while taking into account differences in genotype, genetic background, natural history and clinical presentation, should provide therapeutic algorithms allowing effective and tailored treatment approaches. However, several unanswered questions need to be addressed before reaching this goal. These include, among others, what the best timing is for starting a treatment, how to define a disease progression that should prompt a drug change, what the role is for liver transplantation in light of the novel gene-silencing agents, whether presymptomatic genetic testing should now increasingly be offered to at-risk relatives and when it should be performed. Collaborative studies among international expert centres are also needed to develop more sensitive disease markers to assess patient risk and to better define responses to treatment. The International Society for Amyloidosis or other international scientific societies could then represent the best framework for developing new guidelines to favour optimal patient care and drug accessibility across the continents, hopefully limiting treatment inequalities.

\section{References}

1. Sipe JD, Benson MD, Buxbaum JN, Ikeda SI, Merlini G, Saraiva MJ et al. Amyloid fibril proteins and amyloidosis: chemical identification and clinical classification International Society of Amyloidosis 2016 Nomenclature Guidelines. Amyloid. 2016 Dec;23(4):209-13. https://doi.org/10.1080/13506129.2016.1257986

2. Conceição I, González-Duarte A, Obici L, Schmidt HH, Simoneau D, Ong M, et al. "Red-flag" symptom clusters in transthyretin familial amyloid polyneuropathy. J Peripher Nerv Syst. 2016 Mar;21(1):5-9. https://doi.org/10.1111/jns.12153

3. Mangione PP, Verona G, Corazza A, Marcoux J, Canetti D, Giorgetti $S$ et al. Plasminogen activation triggers transthyretin amyloidogenesis in vitro. J Biol Chem 2018 Jul 17. jbc. RA118.003990. https://doi.org/10.1074/jbc.RA118.003990

4. Maurer MS, Hanna M, Grogan M, Dispenzieri A, Witteles R, Drachman B et al. Genotype and phenotype of transthyretin cardiac amyloidosis: THAOS (Transthyretin Amyloid Outcome Survey). J Am Coll Cardiol. 2016 Jul;68(2):161-72. https://doi.org/10.1016/j.jacc.2016.03.596

5. Pinto MV, Barreira AA, Bulle AS, Freitas MRG, França Junior MC, Gondim FAA et al. Brazilian consensus for diagnosis, management and treatment of transthyretin familial amyloid polyneuropathy. Arq Neuropsiquiatr. 2018;76(9):609-21. https://doi.org/10.1590/0004-282X20180094

6. Adams D, Suhr OB, Hund E, Obici L, Tournev I, Campistol JM et al. First European consensus for diagnosis, management, and treatment of transthyretin familial amyloid polyneuropathy. Curr Opin Neurol. 2016 Feb;29 Suppl 1:S14-26. https://doi.org/10.1097/WC0.0000000000000289

7. Sekijima Y, Ueda M, Koike H, Misawa S, Ishii T, Ando Y. Diagnosis and management of transthyretin familial amyloid polyneuropathy in Japan: red-flag symptom clusters and treatment algorithm. Orphanet J Rare Dis. 2018 Jan;13(1):6. https://doi.org/10.1186/s13023-017-0726-x

8. Ericzon BG, Wilczek HE, Larsson M, Wijayatunga P, Stangou A, Pena JR et al. Liver transplantation for hereditary transthyretin amyloidosis: After 20 years still the best therapeutic alternative? Transplantation. 2015 Sep;99(9):1847-54. https://doi.org/10.1097/TP.0000000000000574

9. Waddington Cruz M, Amass L, Keohane D, Schwartz J, Li H, Gundapaneni B. Early intervention with tafamidis provides longterm (5.5-year) delay of neurologic progression in transthyretin hereditary amyloid polyneuropathy. Amyloid. 2016 Sep;23(3):178-83. https://doi.org/10.1080/13506129.2016.1207163

10. Cortese A, Vegezzi E, Lozza A, Alfonsi E, Montini A, Moglia A et al. Diagnostic challenges in hereditary transthyretin amyloidosis with polyneuropathy: avoiding misdiagnosis of a treatable hereditary neuropathy. J Neurol Neurosurg Psychiatry. 2017 May;88(5):457-8. https://doi.org/10.1136/jnnp-2016-315262

11. Parman Y, Adams D, Obici L, Galán L, Guergueltcheva V, Suhr OB et al. Sixty years of transthyretin familial amyloid polyneuropathy (TTR-FAP) in Europe: where are we now? A European network approach to defining the epidemiology and management patterns for TTR-FAP. Curr Opin Neurol. 2016 Feb;29 Suppl 1:S3-13. https://doi.org/10.1097/WC0.0000000000000288

12. Gillmore JD, Maurer MS, Falk RH, Merlini G, Damy T, Dispenzieri A et al. Nonbiopsy diagnosis of cardiac transthyretin amyloidosis. Circulation. 2016 Jun;133(24):2404-12. https://doi.org/10.1161/CIRCULATIONAHA.116.021612

13. Adams D, Gonzalez-Duarte A, O'Riordan WD, Yang CC, Ueda M, Kristen AV et al. Patisiran, an RNAi Therapeutic, for Hereditary Transthyretin Amyloidosis. N Engl J Med. 2018 Jul;379(1):11-21. https://doi.org/10.1056/NEJMoa1716153

14. Benson MD, Waddington-Cruz M, BerkJL, Polydefkis M, Dyck PJ, Wang AK et al. Inotersen treatment for patients with hereditary transthyretin amyloidosis. N Engl J Med. 2018 Jul;379(1):22-31. https://doi.org/10.1056/NEJMoa1716793

15. Maurer MS, Schwartz JH, Gundapaneni B, Elliott PM, Merlini G, Waddington-Cruz M, et al. Tafamidis treatment for patients with transthyretin amyloid cardiomyopathy. N Engl J Med. 2018 Aug 27. https://doi.org/10.1056/NEJMoa1805689 